\title{
EpiMix Based Novel Vaccine Candidate for Shigella: Evidence of Prophylactic Immunity in Balb/c Mice
}

\author{
Harish Padh ${ }^{3}$ (D) Bhrugu Yagnik ${ }^{1,2} \cdot$ Drashya Sharma ${ }^{1,2} \cdot$ Priti Desai $^{1,4}$ \\ Accepted: 21 December 2020 / Published online: 30 January 2021 \\ (c) The Author(s), under exclusive licence to Springer Nature B.V. part of Springer Nature 2021
}

\begin{abstract}
Multidrug resistant Shigella is one of the leading causes of mortality in children and infants. Availability of vaccine could prevent the Shigella infection and reduce the mortality. Conventional approaches of vaccine development against shigellosis have not resulted in desirable vaccine. As shigellosis may be caused by multiple strains and serotypes, there is a need to develop a multivalent vaccine, capable of providing protection against multiple Shigella strains. To develop broad spectrum vaccine, we had previously derived a pool of conserved epitopes against Shigella by using multiple immunoinformatic tools. In this study, the identified conserved epitopes derived from the Outer Membrane Proteins A and C of Shigella were chemically synthesized, and the EpiMix made up of 5 epitopes coupled to a carrier protein, ovalbumin was developed and validated for its immunogenicity. The intramuscular immunization with EpiMix in Balb/c mice led to increase in EpiMix specific serum IgG, and significant increase in fecal IgA as well as in IL-4, IL-2and IFN- $\gamma$ levels. Further, the EpiMix immunized mice showed protection when challenged against S. flexneri ATCC 12022 using the intraperitoneal route. Moreover, the analysis of cytokine profile and IFN- $\gamma / \mathrm{IL} 4$ ratio in post Shigella challenge immunized mice suggested the high levels of IFN- $\gamma$ levels and possible dominance of Th1 response, playing pivotal role in the elimination of Shigella. Collectively, the results demonstrate the immunogenic potential and protective efficacy of the EpiMix in the murine shigellosis model. However, the detailed study and further optimisation of epitopes would substantiate the prospective use of EpiMix as a prophylactic candidate for vaccination.
\end{abstract}

Keywords Epitopes $\cdot$ Multidrug resistance $\cdot$ Shigellosis $\cdot$ Vaccine $\cdot$ Prophylactic immune protection

\section{Abbreviations \\ OMPs Outer membrane proteins \\ MHC Major histocompatibility complex \\ ELISA Enzyme linked immune sorbent assay}

Harish Padh

hpadh@yahoo.com

1 Department of Cell and Molecular Biology, B.V. Patel Pharmaceutical Education and Research Development (PERD) Centre, Ahmedabad, Gujarat 380054, India

2 BRD School of Bioscience, Sardar Patel University, Vallabh Vidyanagar, Gujarat 388120, India

3 Sardar Patel University, Vallabh Vidyanagar, Gujarat 388120, India

4 Department of Biological Science and Biotechnology, Institute of Advanced Research (IAR), Institutional Area, Koba, Gandhinagar, Gujarat 382426, India

\section{Introduction}

Shigellosis is a disease of the lower intestine which affects millions of people worldwide with an estimated one million fatalities per annum (Kotloff et al. 2018). The susceptible population consists mainly children below the age of 5, pregnant women and immuno-compromised individuals (Niyogi 2005). Antibiotics are preferred as a first line therapy for the treatment of shigellosis, however, in the last decade, multiple strains of Shigella resistant to ampicillin, chloramphenicol, nalidixic acid, tetracycline, trimethoprim sulfamethoxazole, and ciprofloxacin have been isolated from patients in many under developed and developing regions (Ghosh et al. 2011; Pazhani et al. 2008), reducing the effectiveness of available antibiotics (Dutta et al. 2003).Therefore, vaccine development against Shigella has re-emerged as the promising avenue to tackle this public health threat.

Numerous approaches have been deployed to develop a vaccine against shigellosis including genetically attenuated Shigella, killed whole cell vaccines, sub-cellular vaccines, 
and O-polysaccharide-protein conjugates (Phalipon et al. 2008). However, none of these approaches have yet resulted in an effective vaccine. Most of these vaccines have also failed to provide cross-protection against multiple strains of Shigella (Mani et al. 2016). Shigellosis is caused by 4 major strains; $S$. flexneri, $S$. dysenteriae, $S$. boydii, S. sonnei and 50 different serotypes. It is conceivable that the protective response against Shigella is serotype specific (Pédron and Sansonetti 2008). Considering this, the development of a multivalent vaccine capable of providing cross-protection against multiple strains is desirable (Phalipon et al. 2008).

Outer membrane proteins (OMPs) have been considered as potential protective immunogens (Pore and Chakrabarti 2013; McClean 2012; Liu et al. 2012; Mukhopadhaya et al. 2003). We and others have extensively evaluated the immunogenic potential of two of the conserved OMPs; OmpA and OmpC. Our group has previously demonstrated that oral immunization of BALB/c mice with $\mathrm{r}-L$. lactis expressing OmpA of $S$. dysentariae-1induced protective immune response in BALB/c mice (Yagnik et al. 2017b, 2019). We have also demonstrated that the intramuscular immunization with purified recombinant OmpA and OmpC of $S$. dysentariae-1resulted in induction of cross-strain protective immune response against $S$. flexneri ATCC 12022 in a robustly evaluated model of murine shigellosis (Sharma et al. 2017; Yagnik et al. 2019). Epitope based vaccine can enhance the specificity and provide desired immune responses (Toussaint 2011). In this context, we have previously identified a pool of epitopes derived from OMPs of Shigella by a rational and systematic deployment of multiple immunoinformatic tools (Sharma et al. 2016). With the aim to have common epitopes to generate humoral and cell mediated immunity, we derived $\mathrm{T}$ cell epitopes from a pool of B cell epitopes. The epitopes were screened through several selection criteria such as topological surface exposure, binding to maximum Major Histocompatibility Complex (MHC) alleles and high population coverage (Sharma et al. 2016).

In the present study, we have selected a pool of five high scoring epitopes derived from OmpA and OmpC identified previously. These epitopes were then chemically synthesized and validated immunologically in BALB/c mice model for Shigella infection. Following validation, these epitopes were coupled to a carrier protein in order to develop immunologically potent cross-reactive vaccine candidate; "EpiMix" (vaccine preparation containing multiple epitopes). Further, the immunogenicity and protective efficacy of EpiMix was also evaluated and compared to the parental proteins OmpA and $\mathrm{OmpC}$ in a robustly evaluated murine shigellosis model (Sharma et al. 2017). The findings of the present study pave the way towards the development of EpiMix based cross protective and effective Shigella vaccine.

\section{Materials and Methods}

\section{Bacterial Strains and Cultures}

Shigella flexneri ATCC 12,022 was obtained from Biocare Research Pvt. Ltd., Ahmedabad, India. It was grown in nutrient broth under shaking conditions $(180 \mathrm{rpm})$ at $37{ }^{\circ} \mathrm{C}$ for $18 \mathrm{~h}$ in an orbital shaker (Thermo Fischer Scientific, USA). Escherichia coli (E. coli) DH5 $\alpha$ and BL21 (DE3) strains were grown in Luria-Bertani (LB) medium at $37{ }^{\circ} \mathrm{C}$ with vigorous shaking. Kanamycin was used at a final concentration of $30 \mu \mathrm{g} / \mathrm{ml}$ for $\mathrm{r}-E$. coli DH5 $\alpha$ and BL21 strains.

\section{Animals}

Pathogen free, 6 to 8 week old female, Balb/c mice were purchased from Mahaveera Enterprises, Hyderabad, India, and were housed in the animal facility at B. V. Patel PERD Centre as per Committee for the Purpose of Control and Supervision of Experiments on Animals (CPCSEA) guidelines. All animal experiments were performed in accordance with the institutional animal ethics committee.

\section{Peptide Synthesis and Conjugation}

Peptides were synthesized using the method described by Lella and Mahalakshmi (2013), Briefly, all peptides were synthesized by standard solid phase synthesis on a Rink Amide AM resin using Fmoc chemistry. Fmocdeprotection was achieved using $20 \%$ piperidine prepared in dry DMF, and carboxyl group activation was achieved using a mixture of HATU and DIPEA (N,N-ethyldiisopropylamine) (Hünig's base) in dry DMF (dimethylformamide). Three equivalents were used for each coupling and the progress of the reaction was monitored by Kaiser test. Each coupling was repeated at least twice to achieve saturation of all reaction sites. Unreacted sites were not blocked before proceeding to the next amino acid. Progress of the reaction was also monitored using mass spectrometric analysis on a micrOTOF-Q II mass spectrometer (Bruker Daltonik $\mathrm{GmbH}$ ) in methanol. After completion of the synthesis, Fmoc group was deprotected to generate a free $\mathrm{N}$-terminus. Following, DMF was removed using diethyl ether washes and the resin was air-dried. The peptide was simultaneously side-chain deprotected and cleaved from the resin using the following cleavage cocktail: TFA (82.5): water (5.0): phenol (5.0): thioanisole (5.0): ethanedithiol (2.5). $1 \mathrm{ml}$ of resulting cleavage cocktail was used to deprotect $1 \mathrm{mg}$ of dried resin. The cleavage reaction was allowed to proceed for at least $12 \mathrm{~h}$ at $25^{\circ} \mathrm{C}$. After completion of the cleavage reaction, the resin was filtered off and peptide was precipitated using diethyl ether. The 
peptide was repeatedly washed with cold diethyl ether to remove residual cleavage cocktail reagents. The peptide was recovered by centrifugation for $30 \mathrm{~min}$ at $4{ }^{\circ} \mathrm{C}$ at $50,000 \times g$, and finally air dried. The successful synthesis of all the peptides was finally confirmed by mass spectrometric analysis. The obtained peptides were conjugated with Ovalbumin as described previously (Harari et al. 1988).

\section{Immunization with Individual Immunodominant Epitopes}

Five groups of Balb/c mice ( $\mathrm{n}=5$ in each group) were immunized with $50 \mu \mathrm{g}$ of the five individual immunodominant peptides conjugated to Ovalbumin or $50 \mu \mathrm{g}$ of Ovalbumin or PBS alone. All the immunogens were emulsified with Complete Freund's adjuvant for first immunization and Incomplete Freund's adjuvant for subsequent immunizations. Mice were immunized intramuscularly on days $0,14,28$ and 42 . Blood was collected from immunized mice by puncturing retro orbital plexus on days 0, 28, 49 and 56. Subsequently, serum was separated by centrifugation at $1900 \times \mathrm{g}$ for $10 \mathrm{~min}$.

\section{IgG Measurement}

To determine the epitope/antigen specific IgG titres in the sera of immunized mice, Enzyme-linkedImmunosorbent Assay (ELISA) was performed as previously described (Yagnik et al. 2017a, b). The sera obtained on the $56^{\text {th }}$ day from epitope/antigen immunized mice were screened for peptide/ antigen specific IgG antibodies by ELISA. Each well of microtiter plates (Nunc, Thermo scientific) was coated with either $1 \times \mathrm{PBS}$ or $1 \mu \mathrm{g}$ of nonameric peptides or $1 \mu \mathrm{g}$ of EpiMix prepared from unconjugated peptides in equal ratio or $300 \mathrm{ng}$ of purified OmpA or OmpC, and incubated overnight at $4{ }^{\circ} \mathrm{C}$. The uncoated surface was blocked with 2\% Bovine Serum Albumin (BSA) (w/v) prepared in $1 \times \mathrm{PBS}$ and incubated at room temperature (RT) for $3 \mathrm{~h}$. Serially diluted serum samples were added to each well and incubated at RT for $2 \mathrm{~h}$. Thereafter at each step, plates were washed thrice with PBS containing $0.02 \%(\mathrm{v} / \mathrm{v})$ Tween-20 for $2 \mathrm{~min}$. A $100 \mu \mathrm{l}$ of 1:1000 diluted rabbit anti-mouse IgG-HRP was added in each well and incubated for $1 \mathrm{~h}$ at RT. Antibodies were detected by adding $100 \mu \mathrm{l}$ of $1 \times \mathrm{TMB}$ $\left(3,3^{\prime}, 5,5^{\prime}\right.$-Tetramethylbenzidine) substrate. The plates were incubated in dark for $15 \mathrm{~min}$ and a reaction was stopped by adding $50 \mu \mathrm{l}$ of $1 \mathrm{~N} \mathrm{H}_{2} \mathrm{SO}_{4}$. Absorbance was read at $450 \mathrm{~nm}$ by a plate reader (MULTISKAN GO-Thermo fisher Scientific, USA). To monitor the kinetics of epitope/antigen specific serum IgG antibodies, serum was collected from immunized mice on days $0,28,49$ and 56 and antigen specific IgG levels were estimated as described above. The serum samples were diluted to their respective titres.

\section{IgA Measurement}

To estimate the titres of epitope/antigen specific $\operatorname{Ig} \mathrm{A}$ in faecal samples of immunized mice, a $100 \mu \mathrm{g}$ of faecal samples were collected on day $56^{\text {th }}$ post immunization. One ml PBS containing 1\% BSA and 1 mMphenylmethylsulfonyl fluoride (PMSF) was added per $0.1 \mathrm{~g}$ of faecal pellets and incubated for $16 \mathrm{~h}$ at $4{ }^{\circ} \mathrm{C}$. Faecal samples were vortexed thoroughly followed by centrifugation at $16,000 \times g$ for $20 \mathrm{~min}$ at $4{ }^{\circ} \mathrm{C}$ for efficient recovery of faecal SIgA and complete disruption of solid faecal material. A $100 \mu \mathrm{l}$ of serially diluted supernatant was used for ELISA analysis. SIgA was detected using HRP-conjugated goat anti-mouse IgA.

To determine the kinetics of epitope/antigen specific SIgA present in faecal samples of immunized mice, faecesfrom the control and immunized group of mice were collected on days $0,28,49$ and 56 . The $100 \mu \mathrm{g}$ of collected faeces were processed as described above.

\section{EpiMix Immunization and Shigella Challenge}

Following immunological characterization of individual epitopes/peptides, EpiMix preparation was developed by mixing these five immunodominant epitopes/peptides in an equal ratio. Five groups of $B$ alb/c mice( $n=10$ in each group) were intramuscularly immunized with either $50 \mu \mathrm{g}$ of EpiMix or $3 \mu \mathrm{g}$ of OmpA or $3 \mu \mathrm{g}$ of OmpC or $50 \mu \mathrm{g}$ of Ovalbumin or PBS alone on days 0, 14, 28 and 42. All the immunogens were emulsified with Complete Freund's adjuvant for first immunization and Incomplete Freund's adjuvant for the subsequent immunizations. Control group of mice were immunized with PBS alone. Blood was collected from immunized mice by puncturing retro orbital plexus on days $0,28,49$ and 56 and serum was separated by centrifugation at $1900 \times g$ for $10 \mathrm{~min}$. Three mice from each group were sacrificed for spleen collection and assessment of cytokine profile.

On day 63 i.e. 2 weeks after the final immunization, seven mice from each group were challenged intraperitoneally with $5 \times 10^{8} \mathrm{CFU}$ of $S$. flexneri ATCC 12022 in $100 \mu \mathrm{l}$ of PBS (Sharma et al. 2017). The challenge dose of mice was prepared from a frozen stock of S. flexneriATCC 12022 which was harvested at the log phase of growth, estimated to be the optimal time of Shigella invasiveness. Mice were monitored for weight loss, lethargy, fur ruffling and development of conjunctivitis and diarrhea for 7 days after challenge. Three mice from each group were sacrificed within $24 \mathrm{~h}$ of a challenge for monitoring colon length and cytokine assay whereas 4 mice from each group were observed till 7 days after challenge. Faeces from challenged mice were collected $24 \mathrm{~h}$ post challenge and analyzed for the presence of Shigellaby dilution plating on Salmonella-Shigella Agar (SS Agar, Himedia). 


\section{Cytokine Assay}

Spleens were harvested and macerated from control and immunized mice ( $n=3$ animals each on Day 62 and 63) for isolation of the splenocytes using the protocol described previously (Gupta et al. 2011). The splenocytes were cultured in 24-well plate $\left(5 \times 10^{6}\right.$ cells/well $)$ in $1 \mathrm{ml}$ of RPMI 1640 containing 10\% heat-inactivated Fetal Bovine Serum (FBS), $1 \%$ gentamicin, and $1 \% \mathrm{~L}$-glutamine. The splenocytes were primed with either $30 \mu \mathrm{g} / \mathrm{ml}$ of individual peptides/ EpiMix or $3 \mu \mathrm{g} / \mathrm{ml}$ of OmpA or OmpC or PBS alone and incubated for $72 \mathrm{~h}$ at $37{ }^{\circ} \mathrm{C}$ in $5 \% \mathrm{CO}_{2}$. The supernatant was then harvested and stored at $-80{ }^{\circ} \mathrm{C}$ until cytokine analysis. The concentration of selected cytokines (IL-2, IL-4, IL-10 and IFN- $\gamma$ ) was assayed using eBioscience ${ }^{\mathrm{TM}}$ Mouse Th1/Th2 ELISA Ready-SET-Go! ${ }^{\mathrm{TM}} \mathrm{Kit}(\mathrm{eBioscience,} \mathrm{USA)}$ as per manufacturer's instructions and the results were expressed in $\mathrm{pg} / \mathrm{ml}$.

\section{Statistical Analysis}

GraphPad Prism (trial ver. 5) was used to perform all the statistical analyses. Two way ANOVA with Bonferroni's multiple comparison post-hoctest was used to determine the statistical significance of $\operatorname{IgG}$ and $\operatorname{IgA}$ in control and vaccinated animals at the different time points and to determine statistical significance in cytokine levels in control and vaccinated animals re-challenged with different antigens. One way ANOVA with Bonferroni's multiple comparison tests was used to determine statistical significance in colon length, faecal CFU and disease parameters among experimental groups. Data are presented as means \pm standard error of mean (SEM). P values $<0.05$ were considered as significant. For analysis of cytokine after intramuscular immunisation, one way ANOVA with Tukey's multiple comparison post-hoc test was used.

\section{Results}

\section{Epitope Synthesis}

We have previously identified five potent epitopes of OmpA and $\mathrm{OmpC}$, based on the immunoinformatic analysis and prediction of their topological position using GLIDE (Sharma et al. 2016). The amino acid sequences of selected epitopes have been slightly modified for chemical synthesis in this work (Table 1). Topological positions of selected epitopes are shown in the diagram underneath. When we predicted the immunogenicity of modified epitopes using VaxiJen (Table 1), all the modified epitopes/peptides had VaxiJen scores above the threshold value (0.4) indicating their immunogenic potential. After the antigenicity prediction, the nonameric epitopes were synthesized by solid phase synthesis. Mass spectroscopic analysis revealed the single peak of each peptide of desired mass indicating the successful synthesis of the peptide (data not shown). To induce the desired immunogenic response, newly synthesized epitopes were conjugated to the carrier protein, Ovalbumin.

\section{Characterization of Immune Responses Elicited by Epitopes}

\section{Epitope Specific Humoral Response}

In order to ascertain the immunogenic potential of the epitopes, the peptide specific humoral response was analysed. The Ovalbumin conjugated epitopes were individually used for intramuscular immunization of Balb/c mice as described in Fig. 1a. Post immunization, epitope-specific IgG titres were evaluated. Among the five epitopes, P4 demonstrated the highest titre, followed by P3and P2 (Fig. 1b). Additionally, the analysis of epitope specific IgG levels over the course of vaccination revealed that the significant increase in epitope specific $\mathrm{IgG}$ following $3 \mathrm{rd}$ immunization in case of P2, P3 and P4. (Fig. 1c). In contrast, immunization with P1 and P5 did not induce epitope specific serum $\mathrm{IgG}$ titres. The data indicated the immunogenic potential of epitopes P2, P3 and P4.

\section{Epitope Specific Mucosal Response}

Selected epitopes were also evaluated for their ability to generate a mucosal immune response. To address this, we quantified epitope specific sIgA from faecal samples of immunized animals. The maximum epitope specific $\operatorname{SIg} \mathrm{A}$ were raised against $\mathrm{P} 3$, followed by $\mathrm{P} 4, \mathrm{P} 5, \mathrm{P} 2$ and $\mathrm{P} 1$ in the descending order (Fig. 1d). Interestingly, unlike serum $\mathrm{IgG}$, the epitope specific sIgA were observed immediately after the second dose of immunization in case of P3, P4 and P5 (Fig. 1e).

Collectively, the humoral responses suggest the epitopes $\mathrm{P} 3$ and $\mathrm{P} 4$ can induce systemic as well as mucosal immune response.

\section{Cytokine Profiling}

The potential of the epitopes in producing Th1 and Th2 specific cytokines (IFN- $\gamma$, IL-4, IL-2, and IL-10) was also evaluated. As shown in Fig. 1f, P3 immunization leads to significant increase in INF- $\gamma$ level as compared to ovalbumin immunized animals. Similarly, significant increase of IL-2 was observed in the animals immunized with $\mathrm{P} 3$ and $\mathrm{P} 2$ and IL-4 in P3 and P4 as compared to ovalbumin immunized animals. 
Table 1 VaxiJen scores of potential epitopes and their positions on OmpA and OmpC proteins

\begin{tabular}{|l|l|l|l|l|}
\hline Epitope & Original Sequence & Score & $\begin{array}{l}\text { Modified } \\
\text { Sequence }\end{array}$ & Score \\
\hline P1 & FKDHDTGVS & 1.97 & FKDHDTGVS & 1.97 \\
\hline P2 & YKGDNINGA & 1.9671 & YKGENIEGA & 2.11 \\
\hline P3 & YQIQGNSAE & 1.88 & YQIQGESAE & 1.99 \\
\hline P4 & LEYQWTNNI & 0.8202 & LEYQWTNEI & 0.818 \\
\hline P5 & SQYHDTGFI & 0.882 & SQYHDTGFI & 0.882 \\
\hline
\end{tabular}

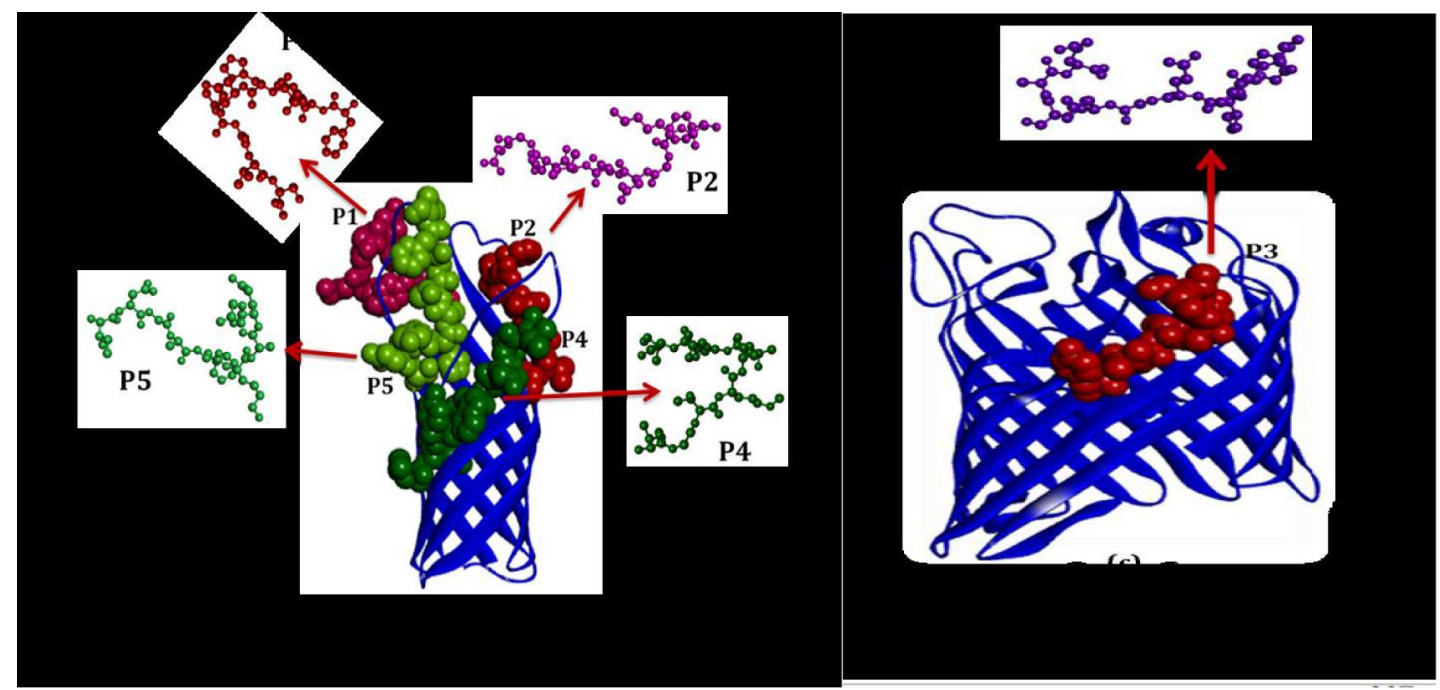

The in vivo immune characterization of cellular and humoral responses elicited by the epitopes reaffirms the immunogenicity of in silico predicted epitopes. All the peptides were able to induce immune response, while some of them successfully induced cellular and humoral arms of immunity. In order to achieve protection against Shigella, activation of both the arms of immune system is desired (Ashida et al. 2015) and since the selected five epitopes generated a spectrum of cellular and humoral immune response, we decided to combine these five epitopes and prepare an EpiMix formulation. The immunogenic and protective potential of EpiMix along with parental proteins OmpA and OmpC was further accessed in a murine shigellosis model.

\section{Immunogenicity and Protective Efficacy of EpiMix}

\section{Humoral Immune Response}

The EpiMix preparation was achieved by conjugating the selected epitopes in the equal molar ratio to the Ovalbumin as mentioned above. EpiMix and parental proteins were used to immunise mice. Immunization protocol and other details of the study design are represented in the Fig. 2a. The sera, collected from the group of immunized mice were used to quantify antigen specific IgG response. As shown in Fig. 2b, significantly higher level of serum IgG titre was obtained with EpiMix, OmpA, OmpC and Ovalbumin as compared to the saline group. The IgG titers of OmpA, OmpC and Ovalbumin were comparatively higher than that of EpiMix. This could be due to the small size of the nonameric epitopes as compared to their parental proteins.

Interestingly, the $\operatorname{IgG}$ titre for EpiMix was much higher as compared to the individual epitopes, indicating the synergistic effect of all five epitopes in boosting humoral response.

As shown in Fig. 2c, OmpA and OmpC were able to elicit significantly higher antigen specific IgG antibodies following the second dose of immunization. Although immunization with EpiMix induced antigen specific immune response, it was not statistically significant.

In order to evaluate the contribution of individual epitopes in generating humoral response following EpiMix immunization, the binding ability of individual epitopes with 


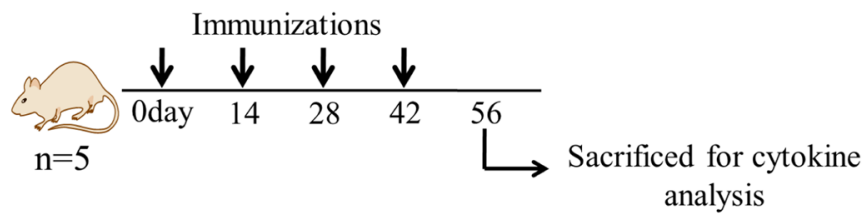

Gaccine $\left.\begin{array}{c}\text { Groups } \\ \text { Control } \\ \text { P1 } \\ \text { P2 } \\ \text { P3 } \\ \text { P4 } \\ \text { P5 }\end{array}\right\}+$ OVA- $50 \mu \mathrm{g}$
PBS

[A]



[B]

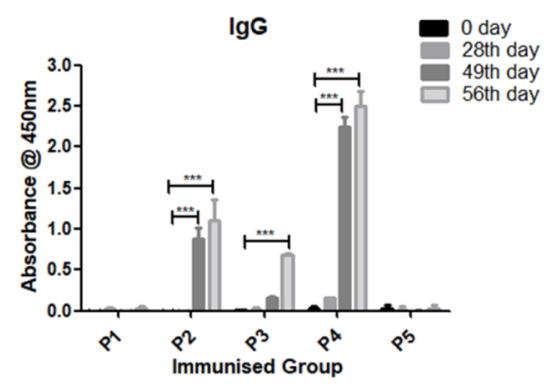

$[\mathrm{C}]$

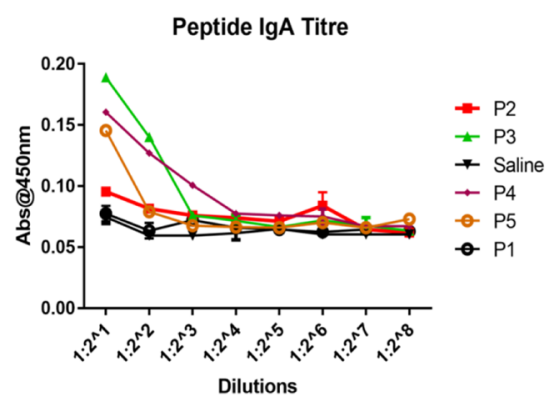

[D]



[E]

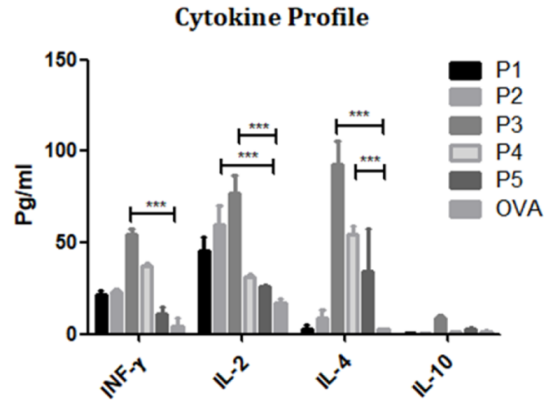

[F]
Fig. 1 Immune characterisation of individual Ovalbumin conjugated epitopes. a Schematic representation of study design. b Epitope specific serum IgG titres obtained after last dose of booster immunization. c Serum IgG levels specific to individual epitopes (P1-P5) obtained at $0,28,49$ and 56 days after immunization. d Epitope specific faecal SIgA titres obtained after last dose of booster immunization. e Faecal SIgA levels specific to individual epitopes (P1P5) obtained at 0,28, 49 and 56 days after immunization. f Cellular response elicited in response to intramuscular immunization of mice

EpiMix specific serum was analyzed. As shown in Fig. 2d while all the epitopes bind to the EpiMix serum, epitopes P3 and P4 were observed to contribute maximally, followed by $\mathrm{P} 2, \mathrm{P} 5$ and $\mathrm{P} 1$.

The antigen specific sIgA was detected in the faecal samples of all vaccine groups; EpiMix, OmpA, OmpCand Ovalbumin. As compared to the control group, immunization with individual epitopes. IFN- $\gamma$, IL-4, IL-10 \& IL-2 levels respectively measured in the supernatant of splenocytes of immunized mice incubated with all five epitopes (P1-P5), ovalbumin and saline. The $* * *$ p value $<0.001, * *$ p value $<0.01$ and $*$ p value $<0.05$. $*$ Here, Sera obtained from mice immunized with saline alone were used as the control. The readings obtained for the control were subtracted from all the other samples in the $\mathbf{c}, \mathbf{e}$ and $\mathbf{f}$ graphs. For $\mathbf{c}, \mathbf{e}$ and $\mathbf{f}$ Two way ANOVA with Bonferroni Post-tests was performed using GraphPad Prism (trial ver. 5)

with EpiMix resulted in higher sIgA titre, however, the titre was lower than that of the parental proteins (Fig. 2e and f). EpiMix specific sIgA titres were higher than obtained for individual epitopes except for P4.

Similar to antigen specific IgG response, the antigen specific sIgA raised significantly after the second immunization in case of OmpA, OmpC and Ovalbumin. It took three 
rounds of immunization of EpiMix to observe significant levels of sIgA (Fig. 2g). Following 3rd dose of immunization, there was a decrease in antigen specific sIgA in case of Ovalbumin immunized mice, while the antigen specific sIgA continued to increase significantly in the animals immunised with OmpA, OmpC and EpiMix on day 56. Taken together, the results indicate the successful induction of mucosal immune response by OmpA, OmpC and the EpiMix.

\section{Evaluation of Protective Efficacy of EpiMix}

In order to evaluate and compare the protective potential of EpiMix and parental proteins/immunogens, the immunized mice were intraperitoneally challenged with $5 \times 10^{8} \mathrm{CFU}$ of S. flexneri ATCC 12022 as described previously (Sharma et al. 2017). Mice immunized with EpiMix, OmpA and OmpC didn't develop any disease symptoms, whereas Ovalbumin and PBS immunized mice developed symptoms similar to human shigellosis as shown in Fig. 3. Reduction in physical activity, ruffled fur, loss of mobility with abdominal swelling, reduction in food intake and severe conjunctivitis with watery inflamed eyes were observed in Ovalbumin and PBS immunized mice, whereas EpiMix, OmpA and OmpC immunized mice were free from all these disease symptoms (Fig. 3a). Additionally, a significant loss in body weight was observed after 24 and $96 \mathrm{~h}$ of the challenge in Ovalbumin and PBS immunized mice, while body weight was retained in rest of the groups (Fig. 3b).

Acute bacillary dysentariae, a hallmark of shigellosis, was developed in Ovalbumin and PBS immunized mice, indicated by soiled anus, loose stool with mucous and blood, whereas EpiMix, OmpA and OmpC immunized mice defecated normal stool (Fig. 3c). Shortening of colon is one of the major indicators of intestinal tissue destruction (Sharma et al. 2017) and was measured at 24 and $96 \mathrm{~h}$ after Shigella challenge. In Ovalbumin and PBS immunized mice, length of the colon was found to be reduced after 24 and $96 \mathrm{~h}$ of challenge, while EpiMix, OmpA and OmpC immunized group didn't show reduction even after $96 \mathrm{~h}$ of Shigella challenge (Fig. 3e).

We also evaluated Shigella shedding in faeces of the challenged mice by the dilution plating on SS agar. The significantly high bacterial load was observed in faecal samples of Ovalbumin and PBS immunized mice while, negligible bacterial count was observed in the rest of the groups (Fig. 3d). These results indicate that immunisation with EpiMix as well as with parental protein protect the Balb/c mice against active Shigella infection.

\section{Cytokine Profile in the Immunised Animals}

Cellular immune responses are integral to protection against Shigella (Tangri et al. 2005). In order to understand the potential and nature of cellular responses elicited by different immunogens, we have evaluated the secretion of a set of Th1 and Th2 cytokines. The splenocytes from the EpiMix immunized animals when stimulated with the either EpiMix, P3 or P4, resulted in significantly higher levels of INF- $\gamma$ as compared to all other vaccine groups (Fig. 4a). Similar to INF- $\gamma$, as shown in Fig. $4 \mathrm{~b}$, the level of IL-2 found to be significantly higher in the splenocytes of EpiMix immunised animals when stimulated with $\mathrm{P} 3$ as compared to other vaccine groups, suggesting the dominance of Th1 cellular immune response. Similarly, levels of IL-4 were found to be the most significantly elevated in the OmpC immunized animals (whose splenocytes were stimulated with OmpC or P3) followed by OmpA immunised animals (whose splenocytes were stimulated with OmpA or P4) and then EpiMix immunised animals (whose splenocytes were stimulated with EpiMix, P5 or P3) (Fig. 4c). Level of IL-10 is comparatively low in all immunised group.

\section{Cytokine Response-Pre vs Post Shigella Challenge}

In order to evaluate how Shigella infection influences the cytokine environment in the control as well as vaccinated animals, we have compared the cellular responses pre- and post-Shigella challenge. As shown in Fig. 5, the levels of all four cytokines (IFN- $\gamma$, IL-2, IL-10 and IL-4) were increased after Shigella challenge as compared to pre challenge time point in all the immunized groups. However, there was no change in cytokine of the PBS treated mice (Fig. 5).

In addition, as shown in Fig. 5 IFN- $\gamma$, IL-2 and IL-4 levels were also increased in Ovalbumin immunized group as compared to control mice. However, these levels are much lower than that of EpiMix, OmpA, OmpC immunized group, an indication of the protective potential of EpiMix, OmpA and OmpC.

\section{Cellular Response}

Moreover, to further characterize the type of cellular response generated by immunization, IFN- $\gamma /$ IL-4 andIL-4/ IFN- $\gamma$ ratios were calculated. Consistent with our previous findings, immunization with OmpA and OmpC demonstrated the high IL-4/IFN- $\gamma$ ratio, indicating the possible dominance of Th2 response (Fig. 5e[I]). On the other side, EpiMix immunization resulted in high (IFN- $\gamma / \mathrm{IL}-4)$ indicating the possible dominance of Th1 response (Fig. 5e[I]).

After intraperitoneal challenge with $S$. flexneri ATCC 12022, the dominance of cellular response was found to be altered in OmpA and OmpC immunized group (Fig. 5e[II]), i.e. the IFN- $\gamma$ surge (high IFN- $\gamma /$ IL-4 ratio) was observed which might indicate the possible dominance of Th1 response. While, the IFN- $\gamma$ surge was consistent in EpiMix immunized group after the Shigella challenge (Fig. 5e[II]). 


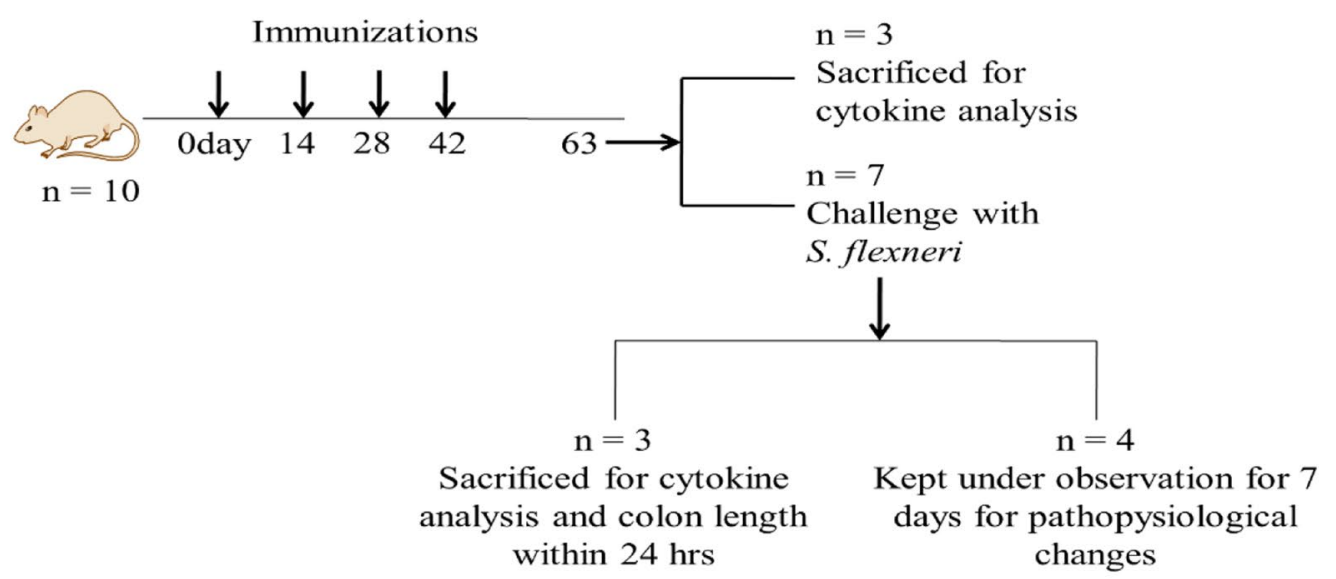

\section{Groups}

Vaccine

EpiMix - $50 \mu \mathrm{g}$

OmpA - $3 \mu \mathrm{g}$

OmpC $-3 \mu \mathrm{g}$

\section{Control}

OVA- $50 \mu \mathrm{g}$

PBS

[A]



[B]

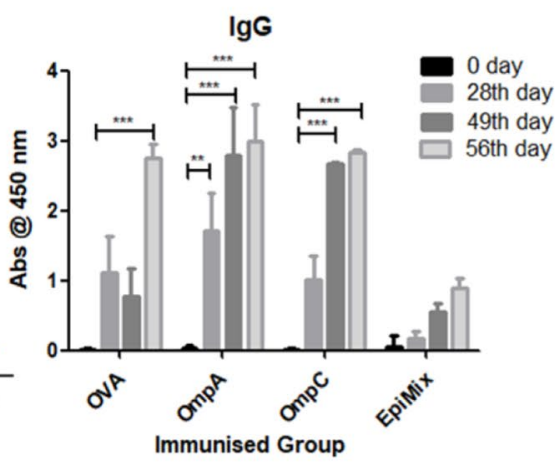

$[\mathbf{C}]$

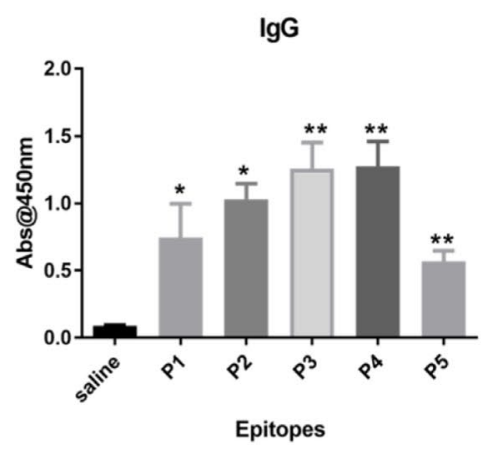

[D]

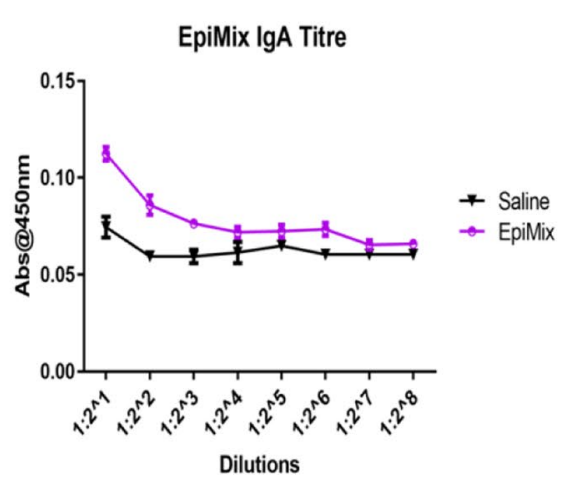

[E]

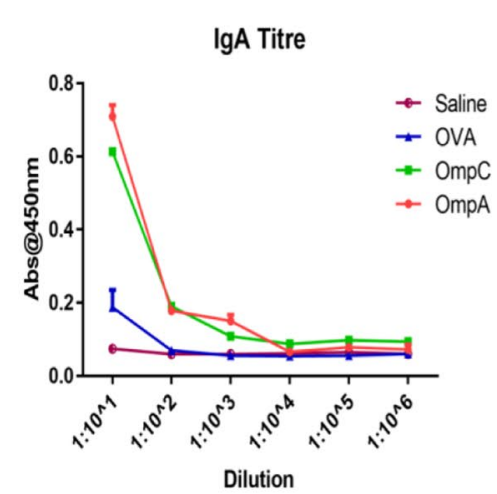

[F]

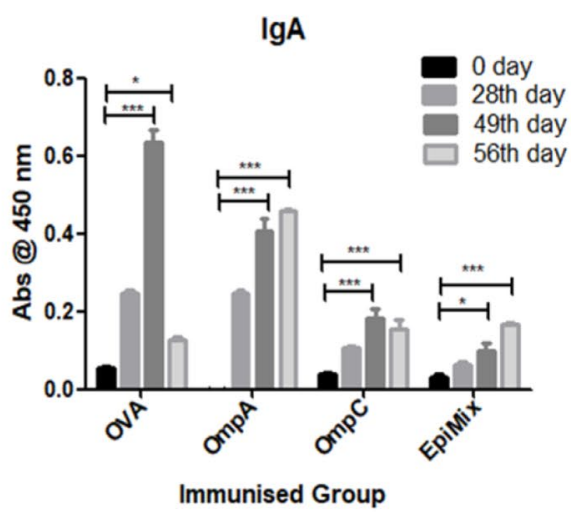

[G] 
4Fig. 2 Humoral and mucosal response elicited after intramuscular immunization of Balb/c mice with EpiMix, OmpA, OmpC, Ovalbimun and saline. a Schematic representation of study design. b Titre determination of serum IgG specific to antigens. c Antigen specific serum IgG levels obtained at $0,28,49$ and 56 days after immunization. d Binding of individual epitopes to EpiMix specific serum IgG. e Titres of EpiMix specific s faecalSIgA elicited post immunization. $\mathbf{f}$ Titres of antigen specific faecalSIgA elicited post immunization. g Antigen specific faecal IgA levels obtained at 0, 28, 49 and 56 days after immunization. The $* * *$ denotes $\mathrm{p}$ value $<0.001$, $* * \mathrm{p}$ value $<0.01$ and $*$ p value $<0.05$. For $\mathbf{d}$ and $\mathbf{g}$ Two way ANOVA with Bonferroni Post hoc tests was performed using GraphPad Prism (trial ver. 5)

The possible dominance of Th1 response after Shigella challenge exhibits its requirement in clearance of intracellular pathogen.

\section{Discussion}

Infectious diseases are one of the leading causes of morbidity and mortality and Shigella is one of the major etiological agentsfor the death of young children under the age of five (Jennison and Verma 2004). The constant research for the development of effective prophylactic has not yet resulted in an effective vaccine, efficacious in lowering the disease burden and alleviate the morbidity.

With the similar aim, extensive efforts have been directed in our lab for the development of candidate vaccine against Shigella infection through the use of conserved antigens and by designing better antigen delivery strategies (Sharma et al. 2016; Yagnik et al. 2016, 2017a, b). Herein, we developed epitope- based vaccine candidate against Shigella. As compared to antigen-based vaccine, an epitope-based vaccine offers several advantages such as increased safety, prospects to rationally modify the epitopes for higher potency, and to generate desired immune responses (Sette and Fikes 2003). Therefore, in the present study five immunologically characterised epitopes derived from antigens OmpA and OmpC were synthesized, and formulated as EpiMix, and tested as putative vaccine candidate. The immunogenic and protective efficacy of EpiMix, along with parent proteins, OmpA and OmpC was evaluated against shigellosis in an appropriate animal model. The study clearly demonstrated that intramuscular administration of EpiMix, OmpA and OmpC elicited protective humoral and cellular immune response, required to prevent the Shigella infection.

The nonameric epitopes in the current work were previously derived by a sequential use of immunoinformatic tools (Sharma et al. 2016) and experimentally validated in subsequent studies (Data in communication). In the present study, five of these epitopes were synthesized and their immunogenic potential was evaluated. The intramuscular immunization of mice with Ovalbumin conjugated epitopes resulted in the generation of epitope specific humoral, mucosal and cellular immune responses. Among the selected epitopes, P4, P3and P2 are capable of inducing significant serum IgG level after 3rd dose of immunisation while significant increase of secretory IgA level were found in the animals immunised with P3, P4 and P5. Similarly, significant enhancement of INF- $\gamma$, IL-2 and IL-4 level were found with P3 immunisation while P2 immunisation enhance IL-2 level and P4 immunisation enhance IL-4 level significantly compared to Ovalbumin control. Elicitation of cell mediated immunity by immunization with epitopes was also reported by other researchers (Berzofsky 2012; Iqbal et al. 2003; Chaitra et al. 2007). Recently, Yang et al., have demonstrated the elicitation of $\mathrm{IgG}$ response specific to individual 18 mer epitopes derived from manganese transport protein C (MntC) of Staphylococcus aureus (2016). Jarab et al., have also exhibited the binding capacity of epitopes derived from OmpC protein with umbilical cord serum IgG (2013).

After confirming the immunogenic potential of synthesized epitopes, the EpiMix was developed using five immunologically characterized epitopes. The intramuscular immunization of EpiMix resulted in EpiMix specific titres of IgG and IgA capable of protecting immunised mice from active Shigella infection challenge, as none of the vaccinated mice developed any disease symptom. The serum IgG and faecal IgA titres specific to EpiMix were lower than that of parent proteins, OmpA and OmpC. Nevertheless, the EpiMix immunized group exhibited complete protection from Shigella infection when challenged with live pathogen. Jackson et. al., also demonstrated the protective efficacy of synthetic peptide vaccine against Listeria monocytogenes (2006). Similar to the present findings, the protective efficacy of a multiepitope based vaccine against methicillin-resistant Staphylococcus aureus (MRSA) was reported by Zhao et al. (2015).

The successful clearance of pathogen involves the activation of cellular response; and therefore cytokine levels were evaluated before and after disease challenge in immunized mice. Immunization with EpiMix successfully induced the high levels of IFN- $\gamma$, IL-4, and IL- 2 compare to parental proteins OmpA and OmpC, indicating the potential of EpiMix to protect mice from shigellosis. Similarly, induction of IFN- $\gamma$ by synthetic peptides was also reported by Tangriet et al. (2005). Moreover, Kurtz et al., demonstrated that peptides derived from type III secretion system of Salmonella also elicited protective levels of IFN- $\gamma$, IL-2 and TNF- $\alpha$ (2014).

Furthermore, the comparison of pre- and post-challenge cytokine levels induced in EpiMix immunized mice revealed significantly high IFN- $\gamma$ levels, a possible dominance of Th1 response. The IFN- $\gamma$ surge might be responsible for preventing bacterial invasion and recruitment of macrophages, involved in clearance of intracellular 


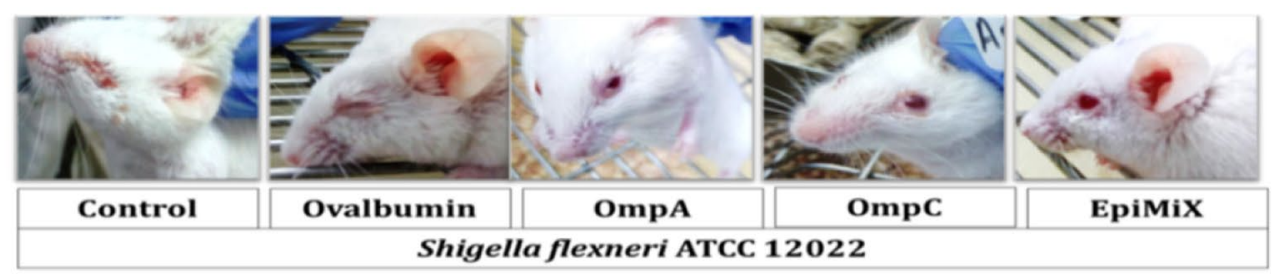

[A]

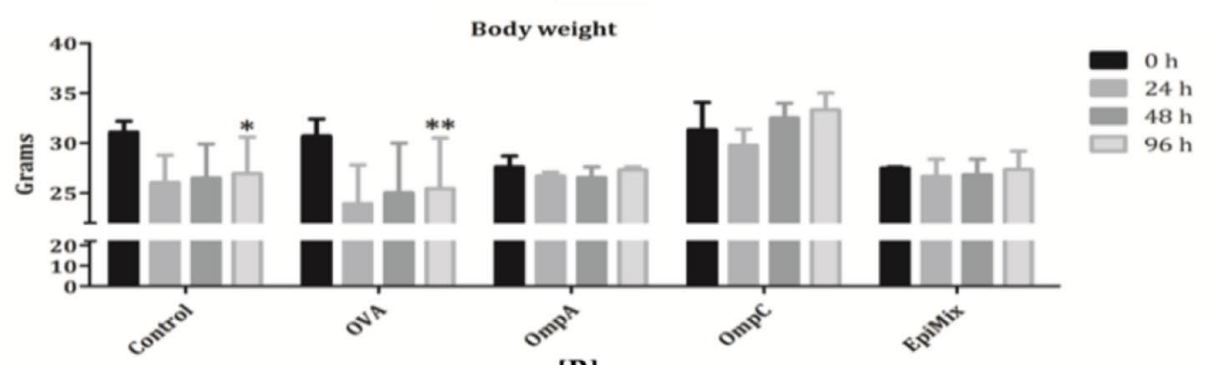

[B]

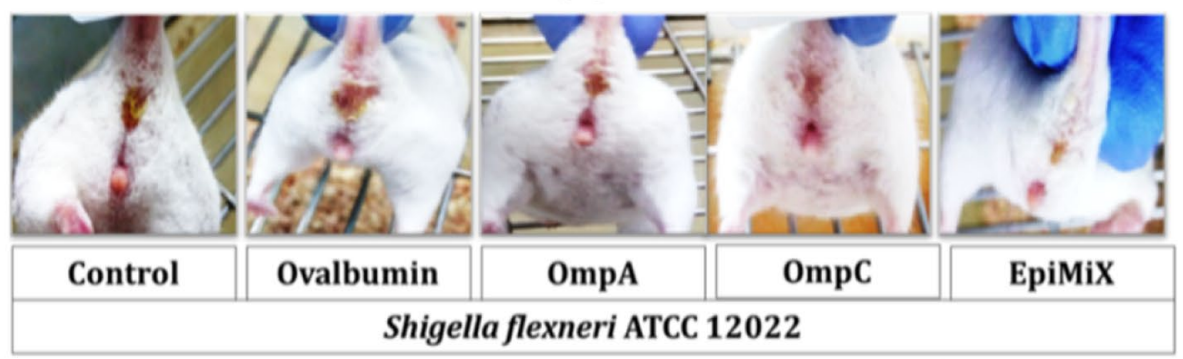

Fecal C.F.U.

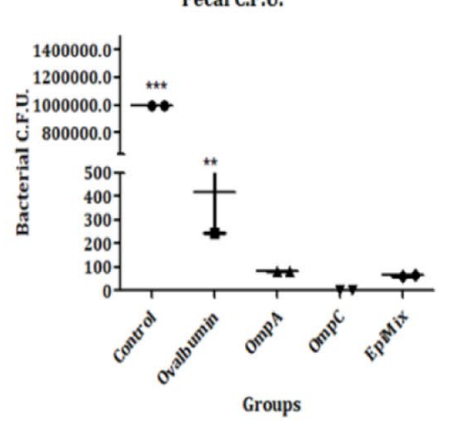

$[\mathrm{C}]$

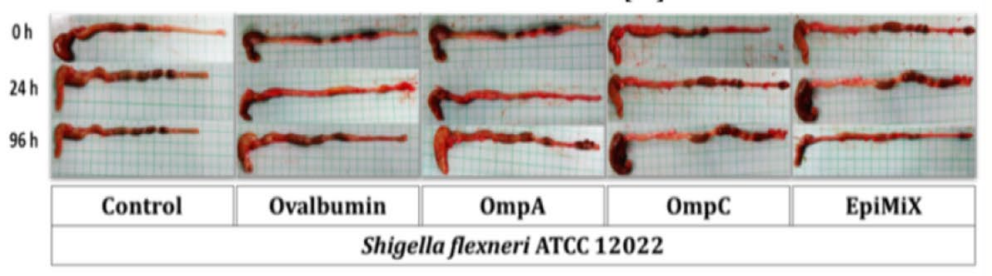

[E]

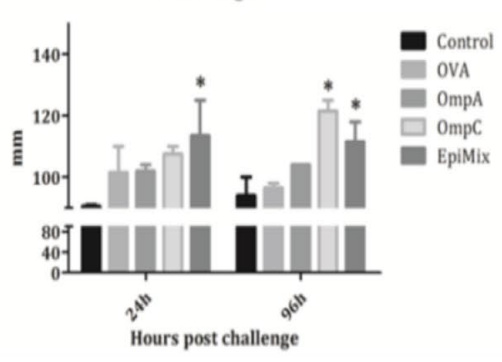

[D]

Fig. 3 Evaluation of protective efficacy of EpiMix, OmpA, OmpC, Ovalbumin and saline immunized mice against intraperitoneal infection of S. flexneri. Pathophysiological characteristics of human like murine shigellosis exhibited by challenged animals such as a Con- junctivitis, b Body weight observed at 0, 24, 48 and $96 \mathrm{~h}$ after disease challenge c Soiled anus d Shigella C.F.U. count present in faeces of challenged mice and e Colon length at 24 and $96 \mathrm{~h}$ after challenge. The $* * * \mathrm{P}$ value $<0.001 * * \mathrm{P}$ value $<0.01$ and $* \mathrm{P}$ value $<0.05$ pathogen like Shigella. On the other side, the IL-10 level was also elevated after disease challenge; probably to counteract the tissue destruction occurred due to Shigella infection. In addition, induction of IL-10 would inhibit the reactive oxygen species generation which is responsible for damaging tissue (Dokka et al. 2001). In the present study, we hypothesize that the vaccination with EpiMix induced the inflammatory and anti-inflammatory cytokines in balance manner, capable of protecting mice from Shigella infection with minimal tissue destruction. The intestinal tissues of post challenge vaccinated animals were near to normal which was evident by the retention of colon length supporting protection of tissue from necrosis. The absence of any blood or mucus in the faeces of EpiMix immunized animals is another indicator of healthy tissue. The vaccination of mice with EpiMix elicited protective mucosal, humoral and cellular responses, essential to prevent the Shigella infection. Further, to achieve significant rise in the EpiMix specific IgG levels, the design/ length of epitopes could be optimised accordingly.

The parental proteins OmpA and OmpC also provided complete protection from Shigella infection which might question the need to develop EpiMix candidate.OmpA and OmpC are not fully conserved among all the Shigella spp 



$[\mathbf{A}]$
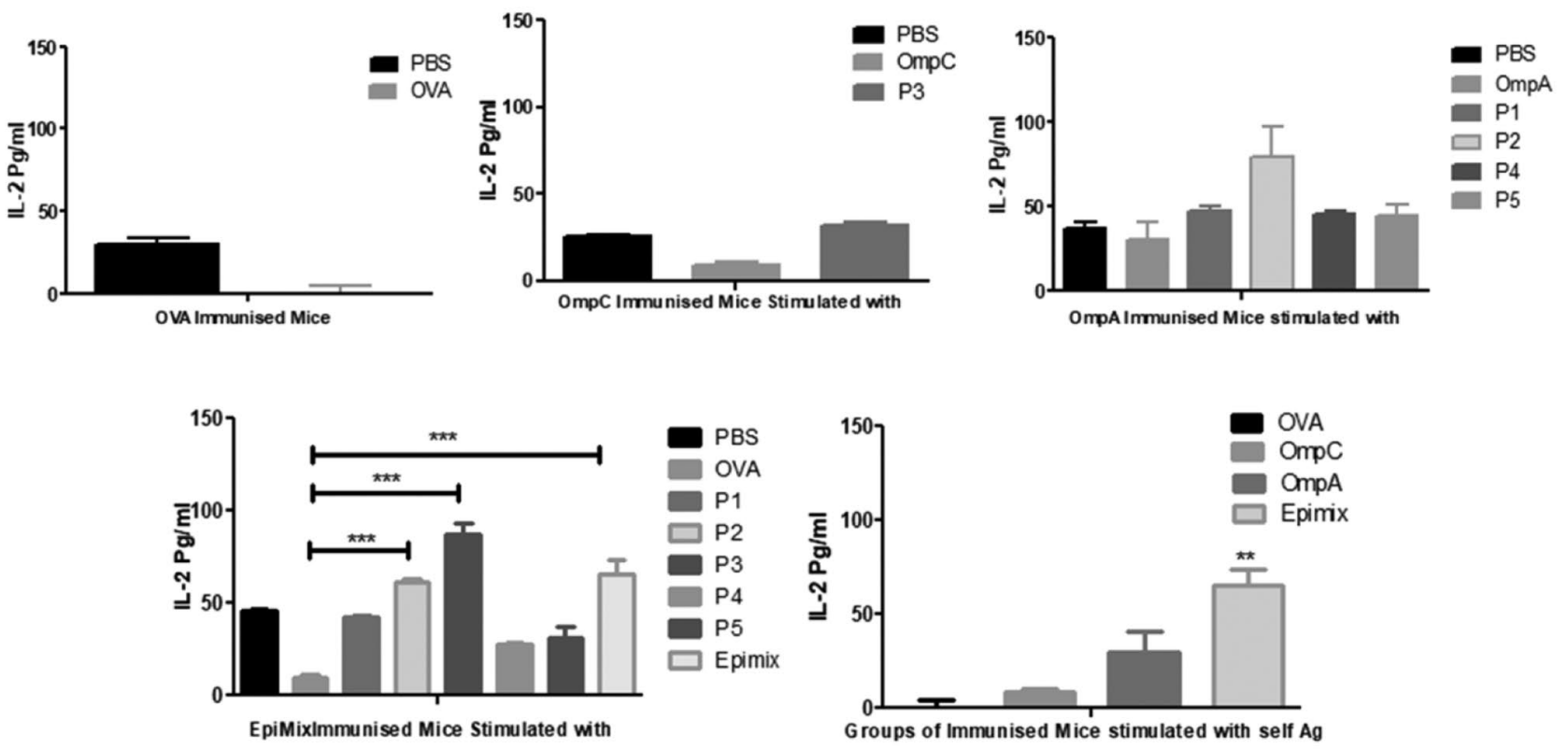

[B]

Fig. 4 Levels of cytokines elicited after intramuscular immunization of Ovalbumin, OmpA, OmpC and EpiMix. a INF- $\gamma$, b IL-2, c IL-4 and d IL-10 levels elicited after the splenocytes stimulated with PBS, Ovalbumin, OmpC, OmpA, EpiMix and with individual peptides (P1, P2, P3, P4 and P5) in the corresponding groups. Statistical test perform: One way Anova, post Tukey's multiple comparison test using
Prism-5 trial version. The $* * * \mathrm{P}<0.0001, * * \mathrm{P}<0.001, * \mathrm{P}<0.05$. Here, supernatant collected from splenocyte culture obtained from mice immunized with saline alone were used as the control. The readings obtained for the control were subtracted from all the other samples 

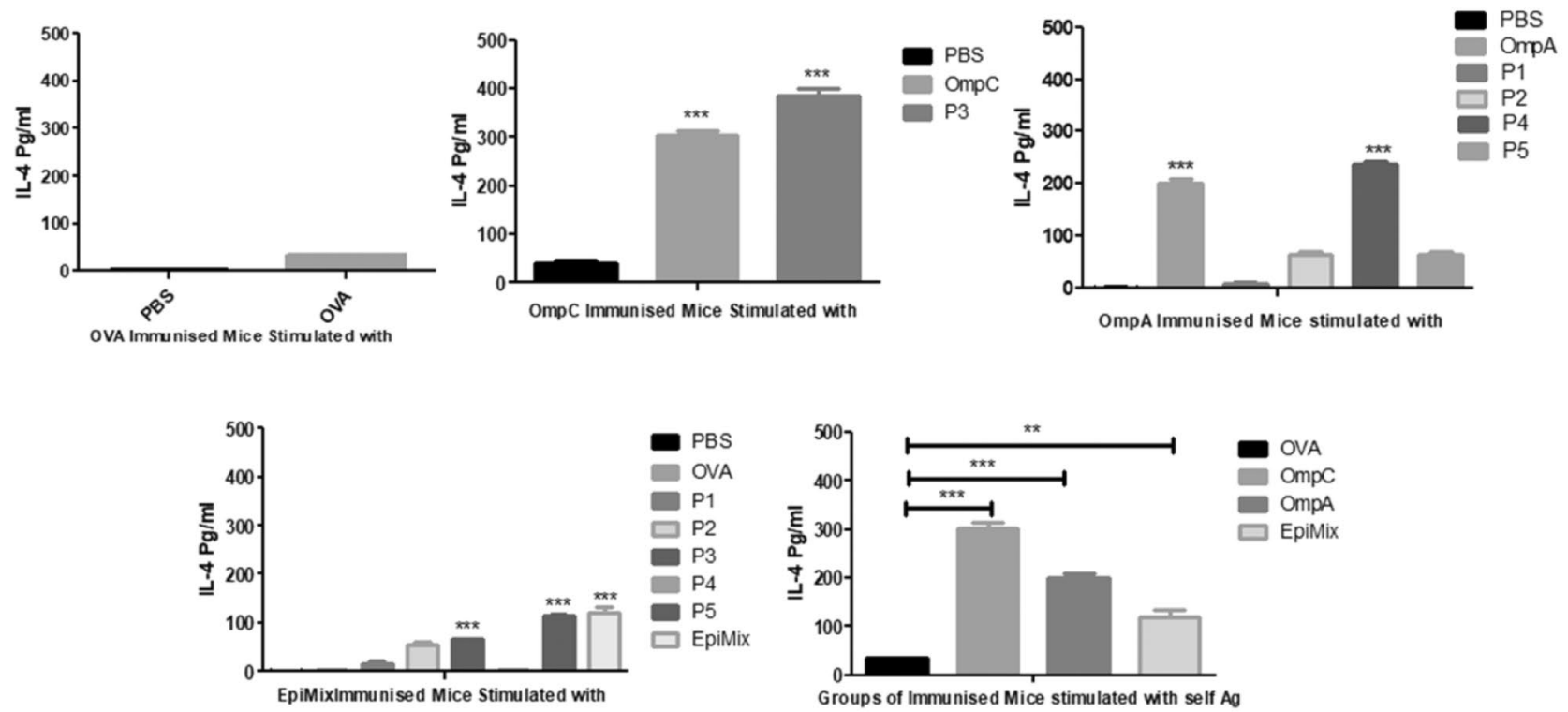

[C]
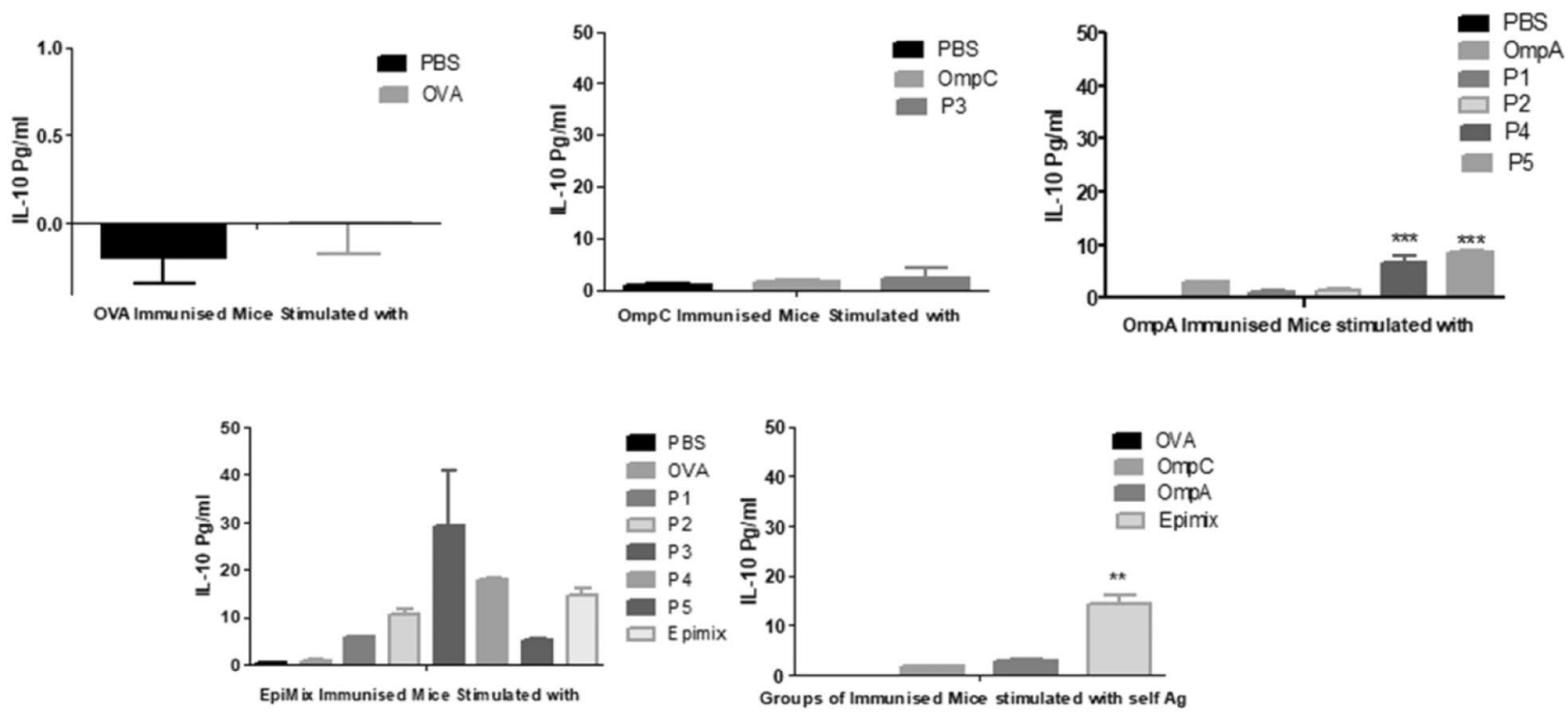

Fig. 4 (continued)

and might not provide complete protection against heterologous challenge of shigellosis.

Additionally, one of the reasons for the failure of full antigen vaccine candidates was their inability to provide protection in geographically distinct population (Oyarzún and Kobe 2015). But, this limitation could be overcome with the aid of immunoinformactics, by identifying the epitopes with population coverage analysis, as deployed in this study.
Therefore, we designed EpiMix, primarily to have a candidate with the OmpA and OmpC epitopes which are conserved in maximum Shigella strains (Sharma et al. 2016). The inclusion of conserved epitopes would enable EpiMix to provide protection against maximum and multiple strains of Shigella spp.

Secondarily, the epitopes included in EpiMix were predicted to be effective in geographically distinct Southeast 
Fig. 5 Comparison of levels of cytokines elicited after intramuscular immunization with Ovalbumin, OmpA, OmpC and EpiMix before and after Shigella flexneri challenge. a INF- $\gamma$, b IL-2, c IL-4 and d IL-10 levels elicited after the splenocytes stimulated with PBS, Ovalbumin, OmpC, OmpA, EpiMix and with individual peptides (P1, P2, P3, $\mathrm{P} 4$ and P5) in the corresponding groups. e Dominance of Th1 or Th2 response exhibited by IFN- $\gamma / \mathrm{IL}-4$ and IL-4/IFN- $\gamma$ ratios. (I) Th1 and Th2 ratios measured in immunized mice before Shigella challenge. (II) Th1 and Th2 ratios measured in immunized mice after Shigella challenge. Two way ANOVA with Bonferroni's multiple comparison post-hoctest was used for this analysis. $* * * \mathrm{P}<0.001$ and $* * \mathrm{P}<0.01$
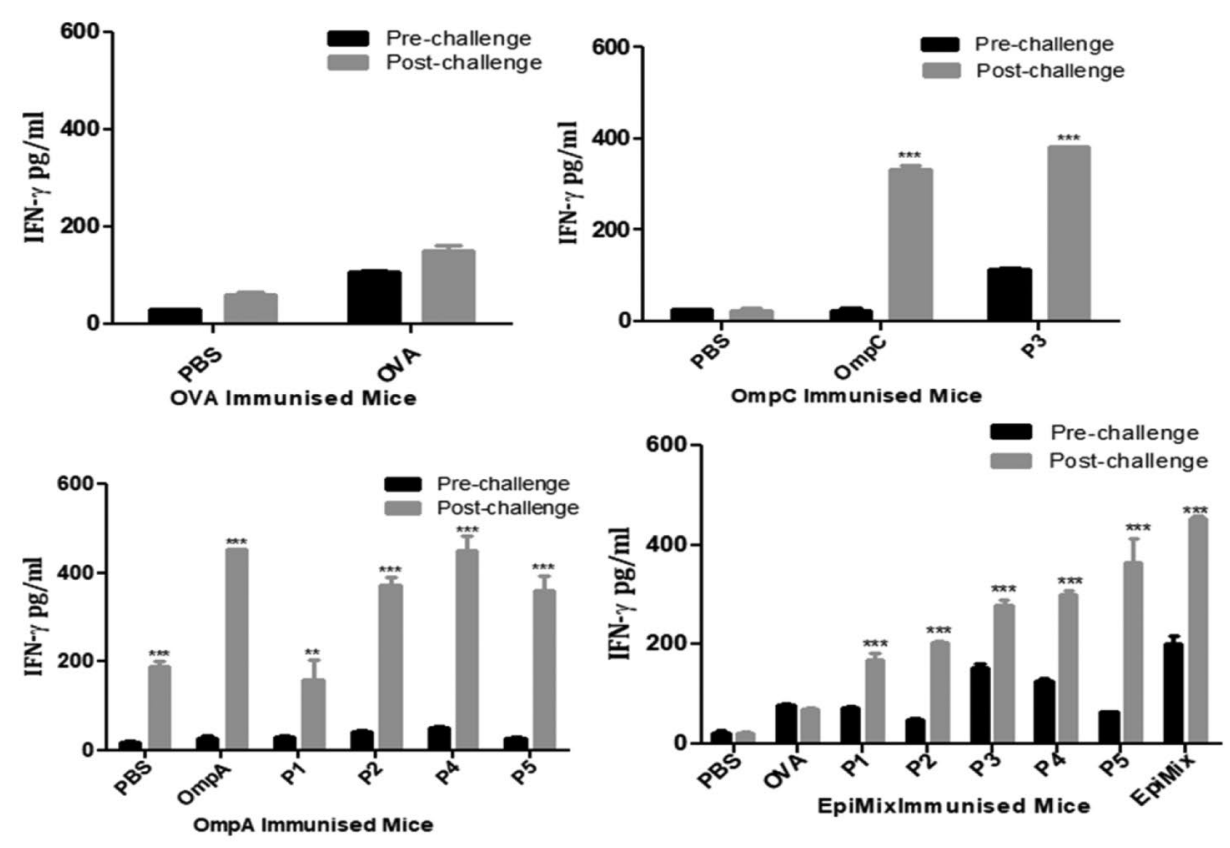

[A]
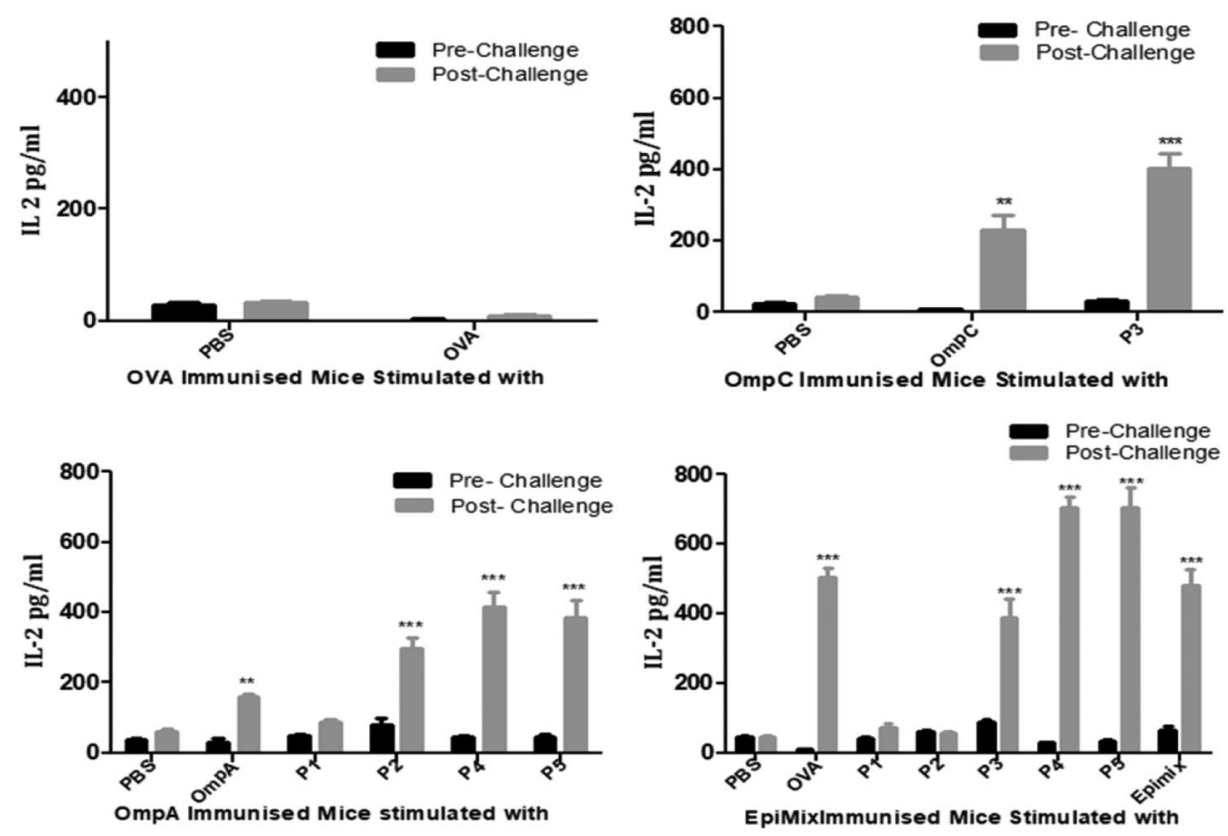

[B]
Asian population by population coverage analysis, therefore we speculate its effectiveness in multinational population. However, further studies are required to analyze the EpiMix's protective efficacy with heterologous Shigella challenge and the epitopes' binding efficiency with patient's sera collected from different geographical location.

\section{Conclusions}

In the present study, the immunogenic potential of newly synthesized epitopes derived from OmpA and OmpC of Shigella was characterized and evaluated. Five selected epitopes of OmpA and OmpC were utilized to develop 
Fig. 5 (continued)


$[\mathrm{C}]$
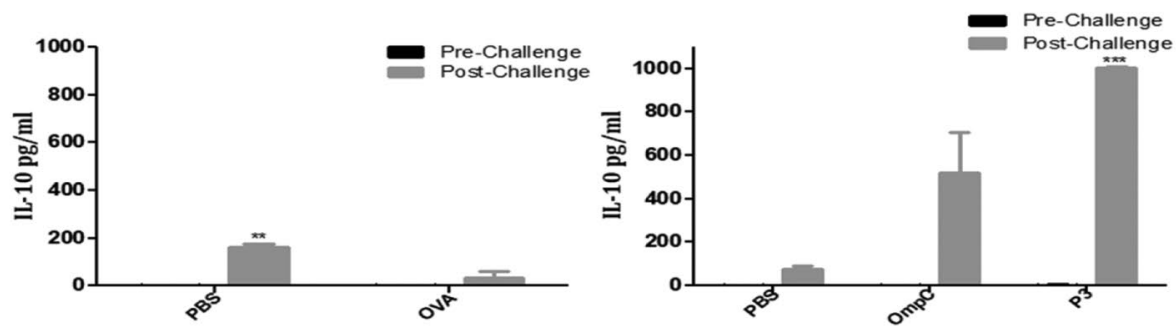

OVA Immunised Mice Stimulated with


[D]

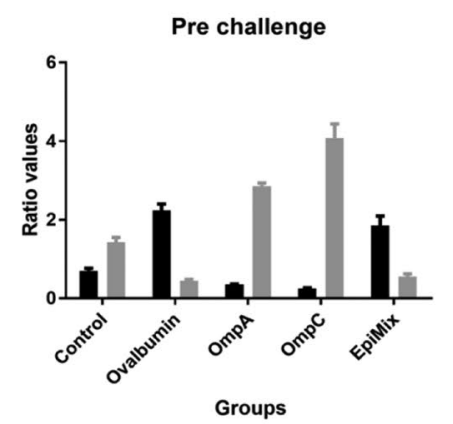

(I)

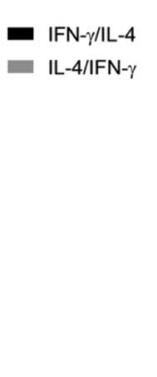

$[\mathbf{E}]$

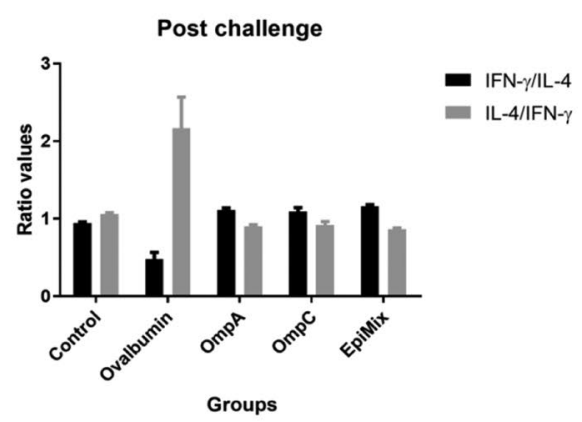

(II) the "EpiMix" against shigellosis. The immunization with EpiMix, OmpA and OmpC resulted in elicitation of antigen specific humoral and mucosal response. The elicited immune responses were effective to protect mice from active infection of S. flexneri. The antigen (OmpA, OmpC, and EpiMix) immunized mice did not develop any 
symptoms of shigellosis. Furthermore, the cytokine profile induced by EpiMix immunization in diseased animals suggested the balance of inflammatory and anti-inflammatory cytokines As the EpiMix was developed with OmpA and OmpC epitopes, the developed candidate "EpiMix" is likely to encompass the immunological activities possessed by both the parental antigens: OmpA and OmpC. The used epitopes are found to be conserved in Shigella spp. and some of the enteric pathogens, the "EpiMix" candidate could be assessed for protective efficacy against other Shigella strains and enteric pathogens. Moreover, the deployed strategy could be used as a platform technology for developing protective prophylactics against other infections.

Acknowledgements We thank B. V. Patel PERD centre for providing the infrastructure facility. Mr. Bhrugu Yagnik is a recipient of Lady Tata memorial fellowship (SRS-2016). The authors also thank Murali Krishna Lella and Radha Krishnan Mahalakshmi, Indian Institute of Science Education and Research, for their help in synthesizing the peptides used in this study.

\section{Compliance with Ethical Standards}

Conflict of interest Authors declare that they have no conflicts of interest.

\section{References}

Ashida H, Mimuro H, Sasakawa C (2015) Shigella manipulates host immune responses by delivering effector proteins with specific roles. Front Immunol 6:219. https://doi.org/10.3389/fimmu .2015.00219

Berzofsky JA (2012) A push-pull vaccine strategy using Toll-like receptor ligands, IL-15, and blockade of negative regulation to improve the quality and quantity of $\mathrm{T}$ cell immune responses. Vaccine 30(29):4323-4327. https://doi.org/10.1016/j.vacci ne.2011.11.034

Chaitra MG, Shaila MS, Nayak R (2007) Evaluation of T-cell responses to peptides with MHC class I-binding motifs derived from PE_ PGRS 33 protein of Mycobacterium tuberculosis. J Med Microbiol. https://doi.org/10.1099/jmm.0.46928-0

Dokka S, Xianglin S, Leonard S, Wang L, Castranova V, Rojanasakul Y (2001) Interleukin-10-mediated inhibition of free radical generation in macrophages. Am J Physiol. https://doi.org/10.1152/ ajplung.2001.280.6.11196

Dutta D, Bhattacharya MK, Dutta S, Datta A, Sarkar D, Bhandari B, Bhattacharya SK (2003) Emergence of multidrug-resistant Shigella Dysenteriae type 1 causing sporadic outbreak in and around Kolkata, India [2]. J Health Popul Nutri. https://doi.org/10.3329/ jhpn.v21i1.189

Ghosh S, Pazhani GP, Chowdhury G, Guin S, Dutta S, Rajendran K, Bhattacharya MK et al (2011) Genetic characteristics and changing antimicrobial resistance among Shigella Spp. isolated from hospitalized diarrhoeal patients in Kolkata. J Med Microbiol, India. https://doi.org/10.1099/jmm.0.032920-0

Gupta P, Singh MK, Singh Y, Gautam V, Kumar S, Kumar O, Dhaked RK (2011) Recombinant shiga toxin B subunit elicits protection against Shiga toxin via mixed Th type immune response in mice. Vaccine. https://doi.org/10.1016/j.vaccine.2011.08.040

Harari I, Donohue-Rolfe A, Keusch G, Arnon R (1988) Synthetic peptides of Shiga toxin B subunit induce antibodies which neutralize its biological activity. Infect Immun 56:1618-1624

Iqbal M, Lin W, Jabbal-Gill I, Davis SS, Steward MW, Illum L (2003) Nasal delivery of chitosan-DNA plasmid expressing epitopes of respiratory syncytial virus (RSV) induces protective CTL responses in BALB/c mice. Vaccine 21(13-14):1478-1485. https ://doi.org/10.1016/S0264-410X(02)00662-X

Jackson DC, Chua BY, Zeng W (2006) Totally synthetic peptidebased vaccines that target dendritic cells and induce potent antibody or CTL responses. Int Congr Ser. https://doi.org/10.1016/j. ics.2005.11.011

Jarzab A, Witkowska D, Ziomek E, Dabrowska A, Szewczuk Z, Gamian A (2013) Shigella flexneri 3a outer membrane protein C epitope is recognized by human umbilical cord sera and associated with protective activity. PLoS ONE. https://doi.org/10.1371/ journal.pone.0070539

Jennison AV, Verma NK (2004) Shigella flexneri infection: pathogenesis and vaccine development. FEMS Microbiol Rev 28:43-58. https://doi.org/10.1016/j.femsre.2003.07.002

Kotloff KL, Riddle MS, Platts-Mills JA, Pavlinac P, Zaidi AKM (2018) Shigellosis. Lancet 391(10122):801-812. https://doi.org/10.1016/ S0140-6736(17)33296-8

Kurtz JR, Petersen HE, Frederick DR, Morici LA, McLachlan JB (2014) Vaccination with a single CD4 T cell peptide epitope from a Salmonella type III-secreted effector protein provides protection against lethal infection. Infect Immun 82:2424-2433. https://doi. org/10.1128/IAI.00052-14

Lella M, Mahalakshmi R (2013) Pro-Gly mediated conformational switch of mycobacteriophage D29 holin transmembrane domain I is lipid concentration driven. Chem Commun (Camb) 49:95949596. https://doi.org/10.1039/c3cc45058a

Liu C, Chen Z, Tan C, Liu W, Xu Z, Zhou R, a, (2012) Immunogenic characterization of outer membrane porins OmpC and OmpF of porcine extraintestinal pathogenic Escherichia coli. FEMS Microbiol Lett 337:104-111. https://doi.org/10.1111/1574-6968.12013

Mani S, Wierzba T, Walker RI (2016) Status of vaccine research and development for Shigella. Vaccine 34:2887-2894. https://doi. org/10.1016/j.vaccine.2016.02.075

McClean S (2012) Eight stranded $\beta$-barrel and related outer membrane proteins: role in bacterial pathogenesis. Protein Pept Lett 19:1013-1025. https://doi.org/10.2174/092986612802762688

Mukhopadhaya A, Mahalanabis D, Khanam J, Chakrabarti MK (2003) Protective efficacy of oral immunization with heat-killed Shigella flexneri 2a in animal model: study of cross protection, immune response and antigenic recognition. Vaccine 21:3043-3050. https ://doi.org/10.1016/S0264-410X(03)00111-7

Niyogi SK (2005) Shigellosis. J Microbiol 43:133-143

Oyarzún P, Kobe B (2015) Recombinant and epitope-based vaccines on the road to the market and implications for vaccine design and production. Hum Vaccin Immunother 12:763-767. https://doi. org/10.1080/21645515.2015.1094595

Pazhani GP, Niyogi SK, Singh AK, Sen B, Taneja N, Kundu M et al (2008) Molecular characterization of multidrug-resistant Shigella species isolated from epidemic and endemic cases of shigellosis in India. J Med Microbiol 57:856-863. https://doi.org/10.1099/ jmm.0.2008/000521-0

Pédron T, Sansonetti P (2008) Commensals, bacterial pathogens and intestinal inflammation: an intriguing Ménage à Trois. Cell Host Microbe 3:344-347. https://doi.org/10.1016/j.chom.2008.05.010

Phalipon A, Mulard LA, Sansonetti PJ (2008) Vaccination against shigellosis: is it the path that is difficult or is it the difficult that is the path? Microbes Infect 10:1057-1062. https://doi.org/10.1016/j. micinf.2008.07.016 
Pore D, Chakrabarti MK (2013) Outer membrane protein A (OmpA) from Shigella flexneri 2a: a promising subunit vaccine candidate. Vaccine 31:3644-3650. https://doi.org/10.1016/j.vacci ne.2013.05.100

Sette A, Fikes J (2003) Epitope-based vaccines: an update on epitope identification, vaccine design and delivery. Curr Opin Immunol 15:461-470. https://doi.org/10.1016/S0952-7915(03)00083-9

Sharma D, Patel S, Padh H, Desai P (2016) Immunoinformatic identification of potential epitopes against shigellosis. Int J Pept Res Ther 22:481-495. https://doi.org/10.1007/s10989-016-9528-6

Sharma D, Yagnik B, Baksi R, Desai N, Padh H, Desai P (2017) Shigellosis murine model established by intraperitoneal and intranasal route of administration: a comparative comprehension overview. Microbes Infect 19:47-54. https://doi.org/10.1016/j.micin f.2016.09.002

Tangri S, Mothe BR, Eisenbraun J, Sidney J, Southwood S, Briggs $\mathrm{K}$ et al (2005) Rationally engineered therapeutic proteins with reduced immunogenicity. J Immunol 174:3187-3196. https://doi. org/10.4049/jimmunol.174.6.3187

Telford JL, Baldari CT (2011) Shigella targets T cells. Cell Host Microbe 9(4):253-254

Toussaint NC (2011) New approaches to in silico design of epitopebased vaccines. http://tobias-lib.uni-tuebingen.de/vollt exte/2011/5856/

Yagnik B, Padh H, Desai P (2016) Construction of a new shuttle vector for DNA delivery into mammalian cells using non-invasive Lactococcus lactis. Microbes Infect 18:237-244. https://doi. org/10.1016/j.micinf.2015.11.006

Yagnik B, Sharma D, Padh H, Desai P (2017a) Dual recombinant Lactococcus lactis for enhanced delivery of DNA vaccine reporter plasmid pPERDBY. Microbiol Immunol 61:123-129. https://doi. org/10.1111/1348-0421.12473

Yagnik B, Sharma D, Padh H, Desai P (2017b) Immunization with $\mathrm{r}$-Lactococcus lactis expressing outer membrane protein $\mathrm{A}$ (OmpA) of Shigella dysenteriae type-1: evaluation of oral and intranasal route of administration. J Appl Microbiol 122:493-505. https://doi.org/10.1111/jam.13353

Yagnik B, Sharma D, Padh H, Desai P (2018) In vivo delivery of pPERDBY to BALB/c mice by LacVax ${ }^{\circledR}$ DNA-I and comparision of elicited immune response with conventional immunozation methods. Gene Ther 25(7):485-496

Yagnik B, Sharma D, Padh H, Desai P (2019) Oral immunization with LacVax ${ }^{\circledR} \mathrm{OmpA}$ induces protectice immune response against Shigella flexneri 2a ATCC 12022 in a murine model. Vacine 37(23):3097-3105

Yang H, Zhang J, Wei C, Yang L, Zuo Q (2016) Immunisation with immunodominant linear B cell epitopes vaccine of manganese transport protein $\mathrm{C}$ Confers protection against Staphylococcus aureus infection. PLoS ONE 11:e0149638. https://doi. org/10.1371/journal.pone.0149638

Zhao Z, Sun H, Wei S, Li B, Feng Q, Zhu J et al (2015) Multiple B-cell epitope vaccine induces a Staphylococcus enterotoxin B-specific IgG1 protective response against MRSA infection. Sci Rep 5:12371. https://doi.org/10.1038/srep12371

Publisher's Note Springer Nature remains neutral with regard to jurisdictional claims in published maps and institutional affiliations. 